\title{
TRANSCRESTAL MAXILLARY SINUS FLOOR ELEVATION USING THE BALLOON TECHNIQUE WITH SIMULTANEOUS IMPLANT PLACEMENT
}

\author{
Ahmed M.Qassem ${ }^{1} B D S$, Nagy P.Hassan²PhD, Magued H.Fahmy ${ }^{2} P h D$
}

\begin{abstract}
\end{abstract}
INTRODUCTION: Rehabilitation of the maxilla using implants is frequently problematic because of the pneumatization of the maxillary sinus into the alveolar ridge. When only a few millimeters of augmentation are needed in conjunction with simultaneous implant placement, an indirect sinus lift is effective. This study describes transcrestal sinus lift using the sinus balloon technique and DASK (Dentium Advanced Sinus Kit) drills for implant placement in patients with an atrophic maxillary posterior area with synthetic bone graft, to evaluate the bone height achieved and the implant success rate.

OBJECTIVES: To evaluate clinically and radiographically the simultaneous implant placement and grafting with synthetic bone graft after Schneiderian membrane elevation using the maxillary sinus balloon technique and DASK drills.

MATERIALS AND METHODS A total of 13 patients with missing posterior maxillary teeth (premolars or molars) and with limited bone height below the floor of the maxillary sinus received an implant and grafting with synthetic bone graft after maxillary sinus lifting using a maxillary sinus balloon technique and DASK drills.

RESULTS: Cone beam computerized tomography 6 months postoperatively showed statistically significant increase in bone height and density. The mean preoperative vertical bone height value was $(5.97 \pm 1.17 \mathrm{~mm})$, while the mean 6 months postoperative vertical bone height value was (10.45 $\pm 1.56 \mathrm{~mm})$. The mean preoperative implant bone density value was (349.6 $\pm 1265.9 \mathrm{HU})$, while the mean postoperative implant bone density was (771.1 $\pm 239.1 \mathrm{HU})$.

CONCLUSIONS: Sinus balloon and DASK drills are an acceptable tool for indirect sinus lifting with simultaneous implant placement. KEYWORDS: Transcrestal approach, sinus balloon technique, DASK drills, implants.

1. Instructor of Oral and Maxillofacial Surgery, Faculty of Dentistry, Alexandria University, Egypt.

2. Professor of Oral and Maxillofacial Surgery, Faculty of Dentistry, Alexandria University, Egypt.

\section{INTRODUCTION}

In the maxillary posterior region, the residual ridge resorption is accompanied by pneumatization of the maxillary sinus. This leads to lack of adequate bone height, and implant placement without bone regeneration is not possible. Implant stability is also higher in the mandible than in the maxilla, which further causes unfavorable conditions for implant placement (1).

Transcrestal sinus lift using the maxillary sinus balloon technique is based on the osteotome transcrestal procedure described by Summers in 1998 (2). The advantage of the balloon technique is that it can be used in the presence of 3 $\mathrm{mm}$ or more of residual bone (3), while conventional transcrestal lift using osteotomes requires a minimum of 6 $\mathrm{mm}$ of residual crestal bone (4). This is because sinus lift with osteotomes affords a height gain of $3 \pm 0.8 \mathrm{~mm}$ (5), while the balloon technique can afford sinus membrane elevations of up to $10 \mathrm{~mm}$ (6).

Muronoi et al. in 2003 (7), and Soltan and Smiler in 2005 (8) described the use of the sinus balloon indirect sinus lift, placing it through a window in the lateral sinus wall. Kfir et al. in 2006 (9) described transcrestal sinus lift using the sinus balloon technique, placing bone grafts and dental implants in the same surgical step. Other authors such as Hu et al in 2009 (10) have also used this technique to place implants in the same step as transcrestal sinus lift.

The use of a sinus balloon has three major advantages: a low risk of perforation of the sinus membrane even in anatomically complex conditions, a low incidence of infection and bleeding, and a shorter operating time (7).
The most common problems encountered during a direct sinus elevation procedure include the presence of septa or the perforation of the membrane. Septae in the maxillary sinus are more commonly seen in partially edentulous patients than in dentate and completely edentulous patients. In addition, the location of septae in the maxillary sinus is more frequent in the middle region (11).

The use of graft materials in the bone defects prevents hematoma formation and acts as a scaffold and promotes bone formation. The degradation of these bone substitutes is necessary as they are ultimate to be replaced by newly formed bone. Resorbable ceramics act as temporary space fillers or scaffolds for new tissue to develop. Natural tissue reconstruction occurs simultaneously with resorption (12).

Therefore, the present study was designed to evaluate clinically and radiographically the simultaneous implant placement and grafting with synthetic bone graft after Schneiderian membrane elevation using the maxillary sinus balloon technique and DASK (Dentium Advanced Sinus Kit) drills.

\section{MATERIALS AND METHODS \\ Informed consent}

Appropriate institutional ethical clearance from the Faculty Ethical Committee and written informed consent from the patients were obtained. All patients were informed about the aim of the designed study.

\section{Patient selection and evaluation}

The study was conducted on 13 patients having resorption of the posterior maxillary ridges where sinus lifting was performed with the use of DASK drills and the sinus 
balloon technique. Thirteen patients were selected from the Outpatient Clinic of Oral and Maxillofacial Surgery Department, Faculty of Dentistry, Alexandria University.

The inclusion criteria of this study were: patients between 20 to 50 years having residual alveolar bone height between 4-8 $\mathrm{mm}$ at the edentulous posterior maxillary region, adequate ridge diameter, inter-arch space and interocclusal space to accommodate implants, abutments and the future prosthesis, free from any sinus pathosis after ear, nose and throat (ENT) consultation, adequate oral hygiene and patients psychologically accepting to participate in the study. While the exclusion criteria were: patients suffering from acute sinusitis, long-standing nasal obstruction, relevant uncontrolled systemic and/or metabolic diseases, immunosuppressive and/or autoimmune diseases, history of radiotherapy or chemotherapy, heavy smokers and parafunctional habits.

\section{MATERIALS}

1. Dentium super line implant system (SuperLine dental implant,\#214, 501 Gyeonggi R\&DB Center, 105 Gwanggyo-ro) is a titanium implant with rounded apex consisting of the internal hex part to be coupled to the superstructure and the tapered Hybrid Double Thread ${ }^{\mathrm{TM}}$ part to be fixed to the bone.

2. The dentium sinus lift balloon (Dentium sinus balloon, \#214, 501 Gyeonggi R\&DB Center, 105 Gwanggyo-ro, Yeongtong-gu, Suwon-si, Gyeonggi-do, Korea) was developed to gently elevate the Schneiderian membrane with minimum trauma and without the use of sharp instruments. The apparatus is a pneumatic device consisting of a $5 \mathrm{ml}$ syringe, polyvinyl chloride (pvc) tubing, with a tip connected to a latex mini balloon with an inflation capacity of approximately $5 \mathrm{~cm} 3$.

3. GUIDOR calc-i-oss CRYSTAL (GUIDOR® calc-ioss CLASSIC, Route de Pallatex 15, 1163 Etoy, Switzerland) consists of a biphasic calcium phosphate (BCP) compound formed in the ratio 60\% Hydroxyapatite and $40 \%$ phase-pure $ß$-tri calcium phosphate (ß-TCP). The material is $100 \%$ alloplastic with no elements of animal or human origin. Macropores provide space for vascularization and bone regeneration. Open micropores of GUIDOR calc-i-oss CRYSTAL allow for optimal fluid circulation.

4. DASK drill \#1 A 3.3-mm-diameter and DASK drill \#2 A3.8 mm diameter (Dentium Advanced Sinus Kit,\#214, 501 Gyeonggi R\&DB Center, 105 Gwanggyo-ro, Yeongtong-gu, Suwon-si, Gyeonggi-do, Korea): crestal approach drills was used to eliminate the remaining bone below the sinus floor, Using minimal pressure to guide the drill apically.

\section{Preoperative phase}

The preoperative clinical examination was performed for all patients: Patients data were collected; name, gender, age, medical and dental history were taken and the oral mucosa of the edentulous area was examined for color, texture, firmness and thickness. All patients were clinically examined by ear nose and throat (ENT) specialist. Also, preoperative evaluation for all patients included panoramic $\mathrm{x}$-ray and cone beam computerized tomography (CBCT), to evaluate the residual ridge height and width, the anatomy of the maxillary sinus, and for virtual treatment planning, as shown in (Figure 1).

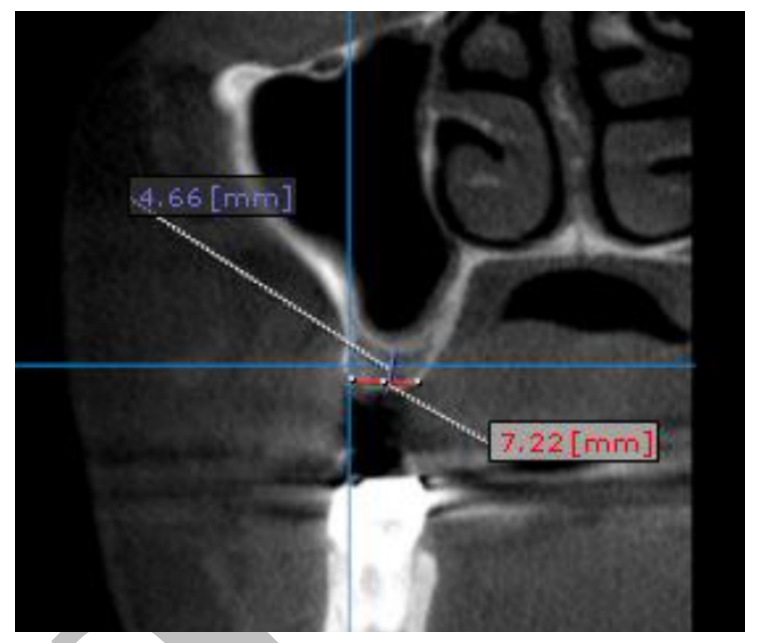

Figure (1): Preoperative CBCT (coronal cut) showing maxillary posterior alveolar ridge height and width.

\section{Surgical procedure}

All patients were operated under local anesthesia using articaine hydrochloride 4\% and levonordefrin 1:100,000 (Septanest; Septodont, France). The oral cavity was prepared by $0.12 \%$ chlorhexidine mouth rinses solution for thirty seconds (Hexitol: Chlorhexidine 125mg/100ml, concentration $0.125 \%$ : Arabic drug company, ADCO) to render the surgical field free from microorganisms. The preformed surgical template was checked for proper seating. Full thickness incision down to the bone with blade no.15, 2 to $3 \mathrm{~mm}$ on the palatal side of the crest of the ridge. A sharp end periosteal elevator was used to perform mucoperiosteal flap and gentle elevation of the flap. The puncture of the bony sinus floor was performed with a customized drilling sequence according to manufacture instructions to the preplanned depth $1 \mathrm{~mm}$ away from the Schneiderian membrane, as shown in (Figure 2).

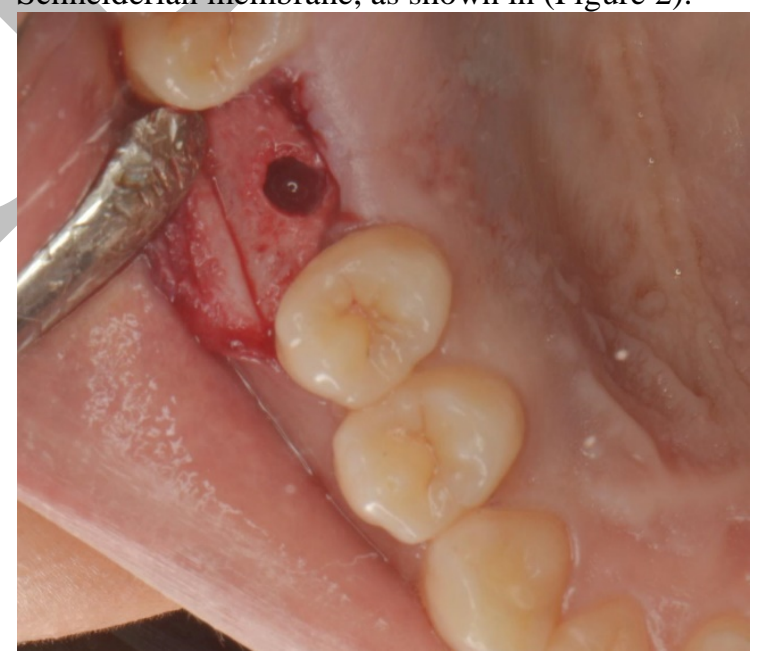

Figure (2): Showing osteotomy site for implant placement.

The remaining subantral bone of $1 \mathrm{~mm}$ was removed using DASK drill of the appropriate size and the sinus floor was carefully approached under light apical pressure, as shown in (Figure 3). When the sinus floor was yielded, the drill was removed. Before placing the sinus balloon within the bone bed, correct functioning of the balloon was checked by insufflating it several times. The balloon was inserted in the subantral space, performing progressive, 
slow and controlled insufflations with saline solution, as shown in (Figure 4). The sinus floor was carefully separated from the Schneiderian membrane using the latex balloon fitted to a catheter used to insufflate the balloon. The sinus balloon was removed from the mouth. The integrity of the sinus membrane was confirmed by asking the patient to blow through the nose after pinching the nostrils, and looking for mist on the mirror. The grafting material (GIDOR calc-i-oss CRYSTAL) of $0.25 \mathrm{ml}$ was introduced using bone graft applicator and pressed into each implant site. The selected implant was carried using the corresponding connector pin and placed into osteotomy site, then threaded using the ratchet wrench. A titanium cover screw supplied with the implant was inserted on the implant with the use of implant screw driver then the flap closed with interrupted sutures, using 3/0 black silk suturing material.

\section{Postoperative phase}

All patients were advised to; apply cold packs extra orally intermittently and avoid hot food on the first day, avoid eating hard food at the surgical site, chlorhexidine mouth rinse was started on the 2nd post-operative day 3 times daily for 10 weeks. Also patients were instructed to avoid sneezing, nose blowing or other actions that might create high intranasal pressure or vacuum, to avoid drinking with straws for a week and not to wear any prosthesis over the surgical site for at least one week after surgery to reduce the risk of wound dehiscence. Sutures were removed one week after surgery.

Postoperative administration of a broad spectrum antibiotic Amoxicillin 875 mg + Clavulanic acid 125 mg tablets (Augmentin $1 \mathrm{gm}$ SmitKhline Beecham Pharmaceutical Co., Bentford, England) every 12 hours for 7 days to avoid post-operative infection. Non-steroidal antiinflammatory analgesic in the form of diclofenac potassium $50 \mathrm{mg}$ tablets (Cataflam $50 \mathrm{mg}$ tablets, Novartis Pharma AG, Basle, Switzerland) every 8 hours for 7-10 days to avoid the possibility of inflammation, oedema and pain. Ephedrine nasal drops (Otrivin spray/nasal Drops $10 \mathrm{ml}$, Novartis Pharma AG, Basle, Switzerland) 3-5 times daily for 5 days.

\section{Follow up phase}

All patients were examined two weeks postoperatively, then after 6 months postoperatively. The clinical parameters of importance for the determination of implant success included: Absence of pain, tenderness, discomfort, wound dehiscence, implant mobility or any other complications related to the sinus lifting or implant placement. Pain and discomfort were examined using visual analogue scale (VAS) (13). Edema was evaluated by its ability to pit according to visual descriptor scale (14).

Immediate cone beam computed tomography (CBCT) was obtained to evaluate the accuracy of implant placement, as shown in (Figure 5).

CBCT was obtained 6 months postoperatively for all patients to measure bone density and the amount of vertical height gained, as shown in (Figure 6).
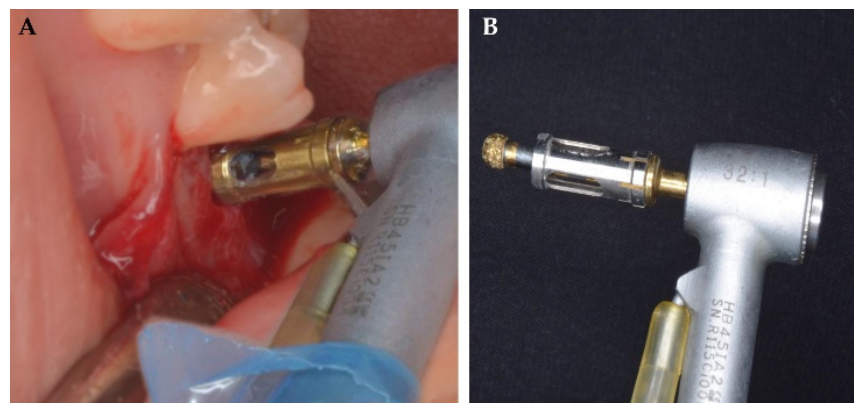

Figure (3): (A) Showing removal of the residual subantral bone using DASK drill. (B)DASK drill \#1mounted on cotra-angled handpiece.
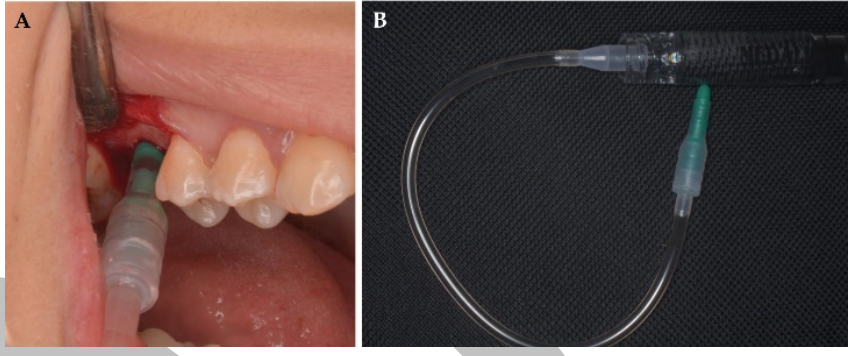

Figure (4): (A) Showing the sinus membrane elevation using the antral membrane balloon. (B) Showing the antral membrane elevation balloon.

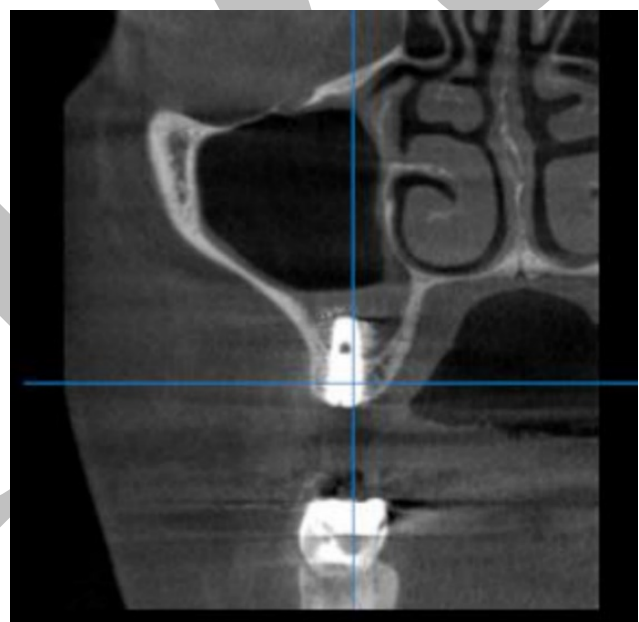

Figure (5): Immediate postoperative CBCT (coronal cut) to evaluate the surgical procedure and implant placement

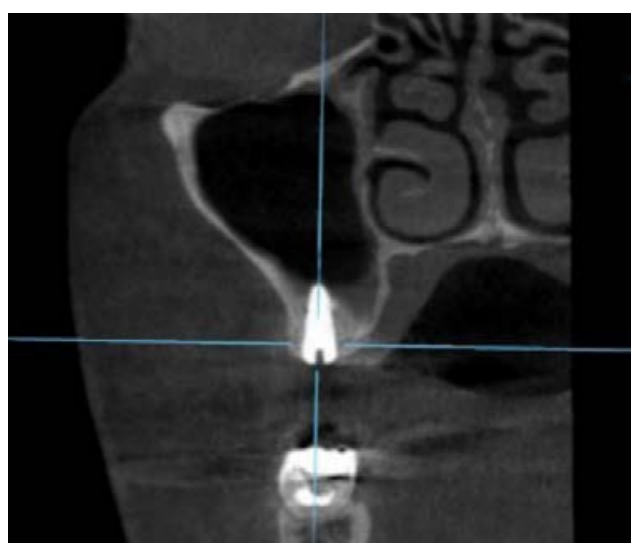

Figure (6): CBCT 6 months postoperative (coronal cut) showing new bone formation. 
CBCT measurements were performed using On Diamond 3D App-DBM software system (Cybernet, Korea) where the bone height could be measured in $\mathrm{mm}$ and through which the bone density is calculated directly in HU.

\section{Prosthetic phase}

Definitive porcelain fused to metal restorations were delivered to all patients at the 6th postoperative month.

\section{Statistical analysis of the data (15)}

Data were fed to the computer and analyzed using IBM SPSS software (Package version 20.0. IBM Corporation, New Orchard Road, Armonk, New York, United States). Quantitative data were described using range (minimum and maximum), mean, standard deviation and median. The distributions of quantitative variables were tested for normality using Kolmogorov-Smirnov test. If it reveals normal data distribution, parametric tests were applied. If the data were abnormally distributed, non-parametric tests were used. For abnormally distributed data, a comparison between two independent population was done using Mann Whitney. The significance of the obtained results was judged at the $5 \%$ level.

\section{RESULTS}

In this study, fourteen sinus floor augmentations were performed on thirteen patients. The selected patients were 3 males and 10 females, and their age ranged from 23-47 years with a mean age of $35.92 \pm 8.61$ years.

Regarding the location of the implant - implants were inserted in the maxillary second premolar spaces and the maxillary first molar spaces.

Fourteen implants were placed; $4 \mathrm{~mm}$ diameter $\times 8 \mathrm{~mm}$ length were placed in two patients, $4 \mathrm{~mm}$ diameter $\times 10 \mathrm{~mm}$ length were placed in six patients, $4 \mathrm{~mm}$ diameter $\times 12 \mathrm{~mm}$ length were placed in two patients, $5 \mathrm{~mm}$ diameter $\times 10 \mathrm{~mm}$ length were placed in three patients and $5 \mathrm{~mm}$ diameter $\times 12$ $\mathrm{mm}$ length was placed in one patient. All patients were followed up both clinically and radiographically for 6 months.

Only one patient was showing positive Valsalva maneuver (16) with appearing of mist on the mirror without air bubbles. In this case implant treatment was completed without bone augmentation, so that the case was excluded from results.

The mean height of the alveolar ridge from the marginal crest to the floor of the maxillary sinus was $5.97 \pm 1.17 \mathrm{~mm}$ (Range: $4.35-7.67 \mathrm{~mm}$ ).

\section{linical evaluation}

\section{Pain}

Pain was evaluated for two weeks. After surgery, five patient experienced mild pain $(\mathrm{VAS}=2-4)$ and three patients experienced moderate pain (VAS=5-7) at surgical site for 1-3 days duration.

\section{Edema}

Four patients suffered from trace oedema, which subsided totally by the 2nd post-operative day, while two patients suffered from mild oedema which lasted for 4 days.

\section{Post-operative complications}

No post-operative complications were recorded regarding infection, wound dehiscence or maxillary sinus involvement in the early follow-up period. Only one patient showed positive Valsalva maneuver with appearing of mist on the mirror without air bubbles. In this case, implant treatment was completed without bone

augmentation, so that the case was excluded from results.

\section{Radiographic evaluation}

CBCT 6 months postoperatively showed statistically significant increase in bone height and density. The mean value of newly formed bone height $(4.48 \pm 1.06 \mathrm{~mm})$. The mean postoperative bone height measured from the floor of the maxillary sinus and alveolar crest was (10.45 \pm 1.56 $\mathrm{mm}$ ) with a range from $7.64-13.15 \mathrm{~mm}$. A significant change was indicated compared to the preoperative bone height, with a mean percentage of change of $77.77 \pm$ $22.76 \%$, as shown in (Table 1 ).

Table (1): Comparison between preoperative and 6 months postoperative residual bone height.

\begin{tabular}{|c|c|c|c|c||}
\hline $\begin{array}{c}\text { Residual } \\
\text { bone height } \\
\text { (mm) }\end{array}$ & $\begin{array}{c}\text { Preoperative } \\
(\mathbf{n}=\mathbf{1 3})\end{array}$ & $\begin{array}{c}\text { After 6 Month } \\
(\mathbf{n}=\mathbf{1 3})\end{array}$ & $\mathbf{t}$ & $\mathbf{p}$ \\
\hline $\begin{array}{l}\text { Min. }- \\
\text { Max. }\end{array}$ & $4.35-7.67$ & $7.64-13.15$ & & \\
$\begin{array}{l}\text { Mean } \pm \\
\text { SD }\end{array}$ & $5.97 \pm 1.17$ & $10.45 \pm 1.56$ & $15.190^{*}$ & $\begin{array}{c}<0.001 \\
\text { Median }\end{array}$ \\
\hline Diff. & \multicolumn{2}{|c|}{$\mathbf{4 . 4 8} \pm \mathbf{1 . 0 6}$} & 10.38 & \\
\hline $\begin{array}{l}\text { \% } \\
\text { Change }\end{array}$ & \multicolumn{2}{|c|}{$\uparrow 77.77 \pm \mathbf{2 2 . 7 6}$} & \\
\hline
\end{tabular}

t, p: $t$ and $p$ values for Paired t-test for comparing between preoperative and after 6 month

*: Statistically significant at $\mathrm{p} \leq 0.05$

The mean preoperative bone density was 349.6 \pm 126.9 $\mathrm{HU}$ and ranged from 188 - $572.3 \mathrm{HU}$. The mean postoperative bone density around the implants after 6 month was (771.1 $\pm 239.1 \mathrm{HU})$ and ranged from (403.3 $1205.8 \mathrm{HU}$ ), which changed significantly compared to the preoperative bone density, with a mean percentage of change $127.4 \pm 36.96 \%$, as shown in (Table 2 ).

Table (2): Comparison between preoperative and 6 months postoperative bone density around implants.

\begin{tabular}{|c|c|c|c|c|}
\hline HU & $\begin{array}{l}\text { Preoperative } \\
\quad(n=13)\end{array}$ & $\begin{array}{l}\text { After } 6 \text { Month } \\
\quad(\mathrm{n}=13)\end{array}$ & t & $\mathbf{p}$ \\
\hline $\begin{array}{l}\text { Min. - } \\
\text { Max. }\end{array}$ & $188.0-572.3$ & $403.3-1205.8$ & & \\
\hline $\begin{array}{l}\text { Mean } \\
\pm \text { SD }\end{array}$ & $349.6 \pm 126.9$ & $771.1 \pm 239.1$ & 10.766 & $<0.001^{*}$ \\
\hline $\begin{array}{l}\text { Media } \\
\mathrm{n}\end{array}$ & 302.9 & 767.2 & & \\
\hline Diff. & \multicolumn{2}{|c|}{$421.56 \pm 141.18$} & & \\
\hline $\begin{array}{l}\% \\
\text { Change }\end{array}$ & \multicolumn{2}{|c|}{$\uparrow 127.4 \pm 39.96$} & & \\
\hline
\end{tabular}

$\mathrm{t}, \mathrm{p}$ : $\mathrm{t}$ and $\mathrm{p}$ values for Paired t-test for comparing between preoperative and postoperative

*: Statistically significant at $\mathrm{p} \leq 0.05$ 


\section{DISCUSSION}

This present study was conducted on 13 patients in need for implant placement for their lost posterior maxillary teeth (premolars and molars) with limited bone height below the floor of the maxillary sinus received an implant and grafted with synthetic bone graft after sinus lifting using the sinus balloon technique and Dask system. They were selected from the Outpatient Clinic of the Oral and Maxillofacial Surgery Department, Faculty of Dentistry, Alexandria University. In this study, twelve patients needed single implants. While one patient needed two implants and grafted with synthetic bone graft after sinus lifting in the second premolar and first molar area.

All patients in the current study were non-smokers. Clementini et al. in 2014 (17) concluded that exposure to smoking has a harmful effect on the peri-implant bone loss that eventually leads to implant failure.

All cases in the present study were selected free from parafunctional habits such as bruxism and clenching, which increase the magnitude of the forces. In such patients, the duration of the forces are extensive and their direction is more horizontal than axial to the implants, which leads to mechanical complications and failure of implants (18).

Patient candidates for sinus floor elevation were carefully assessed by means of case-history collection, complete ENT evaluation with nasal fiberoptic endoscopy and CBCT to be free from any sinus pathosis. This is in agreement with a study conducted by Torretta et al. in 2013 (19), this recommended that a careful multi-tasking preoperative management, including an ENT assessment is useful in patients undergoing sinus membrane elevation to obtain favourable results.

Various imaging options are available for the evaluation of the recipient site. In the present study, panoramic radiographs and CBCT were taken for each patient. These standardized radiographs were taken immediately postoperative and on 6th months follow-up period to measure the marginal bone level and to detect the changes in bone density surrounding dental implants.

In this study, CBCT was performed for all patients preoperatively. Corresponding to the studies conducted by Cassetta et al. in 2013 (20) and Bornstein et al. in 2014 (21), they reported that the use of CBCT in implant dentistry vary from preoperative analysis regarding specific anatomic considerations, site development using grafts and treatment planning to postoperative evaluation. Along with, lower radiation dose, reduced costs and the relative grey density values of CBCT images making it a useful substitute for computerized tomography (CT) $(22,23)$.

The choice of the crestal approach in this study was due to its many advantages in comparison with the lateral approach. First of all, the crestal approach is less aggressive than the lateral approach. Second, the crestal approach is a relatively easier procedure and requires less time for wound healing (24). The main indication of this procedure is the minimally invasive implant treatment single missing tooth in the posterior area of the maxilla with inadequate alveolar bone height, where the conventional lateral approach to augment the sinus with its postoperative morbidity, discomfort, and increased treatment costs would not be required for these patients (25).

The use of thin-out procedure during the sinus augmentation using a diamond drills (DASAK system) reduced the possible intraoperative and postoperative complications. It is safer in cutting, reliable and reduced patient discomfort. These were similar to study reported by Wallace et al. in 2012 (26).

The perforation of the Schneiderian membrane is one of the most frequent intraoperative complication of sinus lift procedures (27). A problem of the transcrstal sinus lift technique is that membrane perforation occurring during surgery cannot be detected with sufficient reliability, because the membrane was not observable through the access hole during surgery.

In the present study, we used Valsalva maneuver to ensure absence of membrane perforation. Perforation was indicated when air bubbles were found or mist appears on the mirror in front of the osteotomy site were found. Valsalva maneuver revealed sinus membrane rupture in one of the patients. In this patient, the size of the perforations occurring during careful displacement of the sinus membrane can be assumed to be small due to the absence of air bubbles and appearance of only mist on the mirror.

This is in agreement with the study of Gabbert et al. in 2009 (28) which was reported that minor perforations do not usually need treatment, because the membrane folds on itself during the elevation in this study, so implant treatment was completed. Several clinical studies also reported that perforation during the transcrestal sinus lifting procedure was not a risk factor for implant survival no complications for implants penetrating the maxillary sinus or the nasal cavity were reported (29-33).

In this case, bone graft augmentation was excluded to prevent Graft dislodgement into the sinus. Schwartz-Arad et al. in 2004 (34) reported that membrane perforations could lead to the infiltration of the particulate graft material inside the sinus and subsequently to inflammation.

In the present study, CBCT obtained 6 months after surgery revealed sufficient newly formed bone in all treated cases. The new bone showed adaptation in shape and volume with the maxillary sinus with a decreased noted visibility of the original sinus floor. The apex of the implants remained surrounded with bone radiographically. This indicated the stability of the newly formed bone and bone maturation. The sinus membrane is maintained elevated and the bone gained is preserved. In addition, the density of the new bone formed around the implants was significant at 6 post-operative months.

In this study, the mean original bone height was $5.97 \pm$ $1.17 \mathrm{~mm}$ preoperatively. Six months after sinus floor augmentation, the mean alveolar bone gain was $10.45 \pm$ $1.56 \mathrm{~mm}$. Thus, the final bone gain was in the range of 403.3 - $1205.8 \mathrm{~mm}$. At 6 months the increase in vertical bone height was found to be statistically significant (pvalue $<0.001$ ). The advantage of the balloon technique is that it can be applied to alveolar crests measuring $3 \mathrm{~mm}$ or less (3), in contrast to the classical indirect technique with osteotomes, where the minimum acceptable crest height is $6 \mathrm{~mm}$ (4). This is because sinus lift with osteotomes affords a height gain of $3 \pm 0.8 \mathrm{~mm}$ (5), while the balloon technique can afford sinus membrane elevations of up to $10 \mathrm{~mm}$ (6).

Similar results were obtained by Kfir et al. in 2009 (35), in a multicenter study of 112 patients subjected to transcrestal sinus lift using the sinus balloon technique, in which the mean remaining crest height was $3.8 \pm 2.1 \mathrm{~mm}$. The mean gain in height after the operation was $8.7 \mathrm{~mm}$, allowing implant placement in the same surgical step. 
The mean bone density of the newly formed bone values was recorded at 6 months postoperatively in Hounsfield unit (HU). The bone density value was found to be $771.1 \pm 239.1 \mathrm{HU}$. At 6 months the increase in the bone density was found to be statistically significant (p-value < 0.001 ). This contributes to the fact that biphasic calcium phosphate crystals are biocompatible, osteoconductive and partially resorbable. The beta-TCP portion is resorbed, while the hydroxyapatite portion remains as a stable, porous scaffold embedded in bone for long-term volume preservation (36).

In the current study implant loading was performed at 6 months postoperatively this is following a study that was conducted by Kim et al. in 2011 (37) to compare the survival rate and surrounding tissue condition of sinus bone grafts with simultaneous implant placement between 4month and 6-month occlusal loading after implantation, and concluded that the cases in which the residual bone was $>3 \mathrm{~mm}$ and primary implant stability could be obtained loading is possible 4 months after the sinus bone graft and simultaneous implant placement with no significance compared to 6 month loading in implant stability.

The cumulative treatment time is reduced due to the combined approach of the grafting procedure with immediate implant placement (the same healing period for both procedures). Reducing the total treatment time minimizes the number of surgical procedures, the pain medications required post-surgically and recovery time, resulting in reducing the total cost of treatment for the patient.

\section{CONCLUSION}

Transcrestal sinus lift using the sinus balloon technique has been a highly successful, predictable and minimally invasive procedure.

\section{CONFLICT OF INTEREST}

The authors declare that they have no conflicts of interest.

\section{REFERENCES}

1. Monje A, Suarez F, Garaicoa CA, Monje F, GalindoMoreno P, García-Nogales A, et al. Effect of location on primary stability and healing of dental implants. I Implant Dent. 2014;23:69-73.

2. Summers RB. Sinus floor elevation with osteotomes. J Esthet Dent. 1998;10:164-71.

3. Kfir E, Goldstein M, Rafaelov R, Yerushalmi I, Kfir V, Mazor Z, et al. Minimally invasive antral membrane balloon elevation in the presence of antral septa: a report of 26 procedures. J Oral Implantol. 2009;35:257-67.

4. Emmerich D, Att W, Stappert C. Sinus floor elevation using osteotomes: a systematic review and meta-analysis. J Periodontol. 2005;76:1237-51.

5. Nkenke E, Schlegel A, Schultze-Mosgau S, Neukam FW, Wiltfang J. The endoscopically controlled osteotome sinus floor elevation: a preliminary prospective study. Int J Oral Maxillofac Implants. 2002;17: 557-66.

6. Stelzle F, Benner KU. Evaluation of different methods of indirect sinus floor elevation for elevation heights of 10 mm: an experimental ex vivo study. Clin Implant Dent Relat Res. 2011;13:124-33.

7. Muronoi M, Xu H, Shimizu Y, Ooya K. Simplified procedure for augmentation of the sinus floor using a haemostatic nasal balloon. Br J Oral Maxillofac Surg. 2003;41:120-1.

8. Soltan M, Smiler DG. Antral membrane balloon elevation. J Oral Implantol. 2005;31(2):85-90.

9. Kfir E, Kfir V, Mijiritsky E, Rafaeloff R, Kaluski E. Minimally invasive antral membrane balloon elevation followed by maxillary bone augmentation and implant fixation. J Oral Implantol. 2006;32:26-33.

10. Hu X, Lin Y, Metzmacher A-R, Zhang Y. Sinus membrane lift using a water balloon followed by bone grafting and implant placement: a 28-case report. Int J Prosthodont. 2009;22:243-7.

11. Orhan K, Seker BK, Aksoy S, Bayindir H, Berberoğlu A, Seker E. Cone beam CT evaluation of maxillary sinus septa prevalence, height, location and morphology in children and an adult population. Med Princ Pract. 2013;22:47-53.

12. Suneelkumar C, Datta K, Srinivasan MR, Kumar ST. Biphasic calcium phosphate in periapical surgery. J Conserv Dent. 2008;11:92-6.

13. Steflik DE, Koth DL, Robinson FG, McKinney RV, Davis $\mathrm{BC}$, Morris CF, et al. Prospective investigation of the single-crystal sapphire endosteal dental implant in humans: ten-year results. J Oral Implantol. 1995;21:8-18.

14. Yokobe J, Kitahara M, Matsushima M, Uezono S. Preference for different anchor descriptors on visual analogue scales among Japanese patients with chronic pain. PLoS One. 2014;9:e99891.

15. Kotz S, Read CB, Vidakovic B. Balakrishnan N. Encyclopedia of statistical sciences. 2nd ed. N.J.: WileyInterscience; 2006.

16. Younes R, Nader N, Khoury G. Sinus Grafting Techniques: A Step-by-Step Guide: Springer; 2015.

17. Clementini M, Rossetti P, Penarrocha D, Micarelli C, Bonachela W, Canullo L. Systemic risk factors for periimplant bone loss: a systematic review and meta-analysis. Int J Oral Maxillofac Surg. 2014;43:323-34.

18. Manfredini D, Poggio CE, Lobbezoo F. Is bruxism a risk factor for dental implants? A systematic review of the literature. Clin Implant Dent Relat Res. 2014;16:460-9.

19. Torretta S, Mantovani M, Testori T, Cappadona M, Pignataro L. Importance of ENT assessment in stratifying candidates for sinus floor elevation: a prospective clinical study. Clin Oral Implants Res. 2013;24:57-62.

20. Cassetta M, Sofan AA, Altieri F, Barbato E. Evaluation of alveolar cortical bone thickness and density for orthodontic mini-implant placement. J Clin Exp Dent 2013;5:e245.

21. Bornstein MM, Scarfe WC, Vaughn VM, Jacobs R. Cone beam computed tomography in implant dentistry: a systematic review focusing on guidelines, indications, and radiation dose risks. Int $\mathrm{J}$ Oral Maxillofac Implants. 2014;29 (1):55-77.

22. Pedroso LAdM, Garcia RR, Leles JLR, Leles CR, Silva MAGS. Impact of cone-beam computed tomography on implant planning and on prediction of implant size. Braz Oral Res. 2014;28:46-53.

23. Chasioti E, Sayed M, Drew H. Novel techniques with the aid of a staged CBCT guided surgical protocol. Case Rep Dent. 2015;2015:439706.

24. Cho S-W, Kim S-J, Lee D-K, Kim C-S. The comparative evaluation using Hatch Reamer technique and osteotome technique in sinus floor elevation. Maxillofacial Maxillofac Plast Reconstr Surg. 2010;32:154-61.

25. Pozzi A, Moy PK. Minimally Invasive Transcrestal Guided Sinus Lift (TGSL): A Clinical Prospective Proof-of- 
Concept Cohort Study up to 52 Months. C Clin Implant Dent Relat Res. 2014;16:582-93.

26. Wallace SS, Tarnow DP, Froum SJ, Cho S-C, Zadeh HH, Stoupel J, et al. Maxillary sinus elevation by lateral window approach: evolution of technology and technique. J Evid Based Dent Pract. 2012;12:161-71.

27. Zijderveld SA, van den Bergh JP, Schulten EA, Christiaan $\mathrm{M}$. Anatomical and surgical findings and complications in 100 consecutive maxillary sinus floor elevation procedures. J Oral Maxillofac Surg. 2008;66:1426-38.

28. Gabbert O, Koob A, Schmitter M, Rammelsberg P. Implants placed in combination with an internal sinus lift without graft material: an analysis of short term failure. J Clin Periodontol. 2009;36:177-83.

29. Brånemark P, Adell R, Albrektsson T, Lekholm U, Lindström J, Rockler B. An experimental and clinical study of osseointegrated implants penetrating the nasal cavity and maxillary sinus. J Oral Maxillofac Surg. 1984;42:497-505.

30. Cavicchia F, Bravi F, Petrelli G. Localized augmentation of the maxillary sinus floor through a coronal approach for the placement of implants. Int J Periodontics Restorative Dent. 2001;21:475-85.

31. Jung J-H, Choi B-H, Zhu S-J, Lee S-H, Huh J-Y, You T$\mathrm{M}$, et al. The effects of exposing dental implants to the maxillary sinus cavity on sinus complications. Oral Surg Oral Med Oral Pathol Oral Radiol Endod. 2006;102:602-5.

32. Jensen J, Sindet-Pedersen S, Oliver AJ. Varying treatment strategies for reconstruction of maxillary atrophy with implants: results in 98 patients. J Oral Maxillofac Surg. 1994;52:210-6.

33. Raghoebar G, Batenburg R, Timmenga N, Vissink A, Reintsema H. Morbidity and complications of bone grafting of the floor of the maxillary sinus for the placement of endosseous implants. Mund Kiefer Gesichtschir. 1999;3:S65-9.

34. Schwartz-Arad D, Herzberg R, Dolev E. The prevalence of surgical complications of the sinus graft procedure and their impact on implant survival. J Periodontol. 2004;75:511-6.

35. Kfir E, Goldstein M, Yerushalmi I, Rafaelov R, Mazor Z, Kfir V, et al. Minimally invasive antral membrane balloon elevation - results of a multicenter registry. Clin Implant Dent Relat Res 2009;11(1):e83-91.

36. Lee JH, Jung UW, Kim CS, Choi SH, Cho KS. Histologic and clinical evaluation for maxillary sinus augmentation using macroporous biphasic calcium phosphate in human. Clin Oral Implants Res. 2008;19:767-71.

37. Kim Y-K, Kim S-G, Park J-Y, Yi Y-J, Bae J-H. Comparison of clinical outcomes of sinus bone graft with simultaneous implant placement: 4-month and 6-month final prosthetic loading. Oral Surg Oral Med Oral Pathol Oral Radiol Endod. 2011;111:164-9. 